\title{
Special Issue on Active Learning and Teaching in Legal Education
}

\section{Editorial}

Bart van Klink, Hedwig van Rossum \& Bald de Vries*

On 3 November 2017, the Netherlands Socio-Legal Studies Association (VSR) and the Netherlands Association for Philosophy of Law (VWR) held a one-day workshop at Utrecht University on new perspectives on active learning and teaching in legal education. This special issue of Law \& Method covers some of the presentations given that afternoon.

The reason for the workshop was the shared belief that in legal education we need to challenge students to think differently about law, showing them a variety of perspectives on how to study and understand the subject. Essentially, students should be able to discover their own voice and to understand and assess legal concepts against the background of a rapid changing social reality. Against this background, the workshop addressed the question of how best to teach law, exploring creative and active ways of learning and teaching. This special issue reports on seven of the presentations that were delivered during the workshop.

The workshop kicked off with a keynote presentation by Maksymillian Del Mar, who talked about image and imagination in legal education. ${ }^{1}$ His contribution is the first in the line-up of this issue. Del Mar argues that if imagination plays a crucial role in legal thought, it is equally crucial that we educate imagination in law schools. He introduces a basic model of legal imagination and then offers some resources on how to develop the variety of abilities exercised in imagining. Literature is a means to activate creative thinking and explore avenues of imagination. Turkish scholar Irem Aki reported on her experience in teaching legal concepts through literature against the background of Turkish political reality. ${ }^{2}$ To make students understand legal terms such as 'rules', 'morality', 'principles', 'equality', 'validity', and 'value judgments', it is necessary to discuss the relation

* $\quad$ Bald de Vries is lecturer at the Department of Jurisprudence, Constitutional and Administrative Law of the Faculty of Law (JCAL), Utrecht University, Utrecht, The Netherlands. Bart van Klink is Professor of Legal Methodology, Faculty of Law, Vrije Universiteit Amsterdam, The Netherlands. Hedwig van Rossum is lecturer-researcher in the Department of Legal Theory at the Vrije Universiteit Amsterdam, Amsterdam, The Netherlands.

1 http://www.lawandmethod.nl/tijdschrift/lawandmethod/2018/10/lawandmethod-D-18-00007.

2 http://www.lawandmethod.nl/tijdschrift/lawandmethod/2018/11/lawandmethod-D-18-00006. 
between law and justice. According to Aki, literature can be used to achieve this aim. Bald de Vries explores how students can use poetry as a means to think about law. ${ }^{3}$ His contribution reports on an experiment in which students write poetry as a strategy to understand philosophical texts, drawing upon the work of James Boyd White and the poet Shelley.

Understanding and imagining law demand a critical attitude and the ability to challenge law and discuss legal outcomes. Hence, critique is a valuable and important skill for a law student. This, however, requires students to be able to translate thought into text and thus to comprehend and process a particular legal theme. In her contribution, Renetta Bos shows how 'basic building blocks maps' can be used as a didactic tool to help students to understand legal concepts and their interrelation. ${ }^{4}$ Bos argues that this didactic tool will enable students to process information and knowledge in a meaningful way. Bart van Klink and Lyana Francot explore the value of critique for legal learning, conceived as an academic activity. ${ }^{5}$ Students should be able to go beyond merely expressing their opinions, to evaluate and criticise a certain practice, building on a sound argumentation, and give suggestions on how to improve this practice. Criticism not only entails a negative judgment but is also constructive, as it aims at challenging and changing the current state of affairs. In their contribution, Van Klink and Francot show how they train critical writing in the legal skills course for first-year law students.

Studying law is dominated by text and words - case law, legislation, textbooks and scholarly articles - and often steeped in seriousness. But there are other means to study and understand law. Hedwig van Rossum introduces the concepts of play and playfulness in her contribution. ${ }^{6}$ While 'academic' is not always associated with playfulness, a large part of academic work is, according to Van Rossum, the result of being explorative and playful. She explores play and playfulness as tools for learning in legal philosophical courses, reporting upon her experience in class. Finally, law is also about understanding context, being able to observe a situation, be it in court or elsewhere. In his contribution, Marc Simon Thomas provides a practical introduction to how to organise participant observation as a sociological technique and method. It is a method to collect and analyse data. ${ }^{7}$ Simon Thomas explains how this method of participant observation can be useful for law students.

http://www.lawandmethod.nl/tijdschrift/lawandmethod/2019/1/lawandmethod-D-18-00011. http://www.lawandmethod.nl/tijdschrift/lawandmethod/2019/1/lawandmethod-D-19-00002. http://www.lawandmethod.nl/tijdschrift/lawandmethod/2019/1/lawandmethod-D-18-00010. http://www.lawandmethod.nl/tijdschrift/lawandmethod/2018/11/lawandmethod-D-18-00005. http://www.lawandmethod.nl/tijdschrift/lawandmethod/2019/1/lawandmethod-D-19-00001. 
The special issue aims at exchanging 'best practices' in order to inspire legal educators and to give concrete tools to translate the didactic ideas into practice. The contributions have, in the main, the practical purpose of sharing experiences on educational experiments and practices. They do not deal extensively with the academic literature on the topic. For this reason, the editors decided not to use the regular double-blind peer review procedure but instead to give constructive feedback on the concept texts and invited external reviewers to do the same. We are grateful to the reviewers for their useful comments, which helped to improve the articles.

Finally, we hope that the special issue inspires colleagues to think differently about teaching law and to use alternative didactic methods, challenging students to think about law and life in many different ways and help them discover their own voice in ongoing discussions about law, its basic principles and values. 